\title{
BIOLOGIA REPRODUTIVA DE Sideroxylon obtusifolium (Roem. \& Schult.) T.D. Penn. (Sapotaceae) NA REGIÃo SEMIÁRIDA DA BAHIA ${ }^{1}$
}

\author{
Lúcia Helena Piedade Kiill², Carla Tatiana De Vasconcelos Dias Martins ${ }^{3}$ e Paloma Pereira da Silva ${ }^{4}$
}

\begin{abstract}
RESUMO - O objetivo deste trabalho foi estudar a fenologia, biologia reprodutiva e visitantes florais de Sideroxylon obtusifolium em área de caatinga. O estudo foi realizado de outubro de 2003 a setembro de 2005, em populações naturais de S. obtusifolium, na Reserva Legal do Projeto Salitre, em Juazeiro, BA. Os dados fenológicos indicaram que as fenofases vegetativas (brotação e senescência foliar) ocorreram ao longo do ano, enquanto a floração e frutificação foram registradas na estação seca e das chuvas, respectivamente. As flores são hermafroditas, de coloração creme, exalam odor, secretam pequena quantidade de néctar $(<1 \mu 1)$ e apresentam antese diurna e dicogamia protogínica. Entre os visitantes florais, foram registradas abelhas, vespas, moscas e borboletas. Apis mellifera e os dípteros morfoespécie 1 e 2 foram considerados polinizadores dessa sapotácea. Quanto ao sistema de reprodução, S. obtusifolium é autógama facultativa, produzindo frutos por autopolinização $(6,6 \%)$ e por polinização cruzada (33\%). Diferenças no registro fenológico, na biologia floral e nos agentes polinizadores foram encontradas, em comparação com outros ambientes, indicando que as variáveis climáticas podem ser um dos diversos fatores que influenciam essa relação.
\end{abstract}

Palavras-chave: Caatinga; Protoginia; Miofilia.

\section{REPRODUCTIVE BIOLOGY OF Sideroxylon obtusifolium (Roem. \& Schult.) T.D. Penn. (Sapotaceae) IN THE SEMIARID REGION OF BAHIA}

\begin{abstract}
The aim of this work was to study phenology, reproductive biology and flower visitors of Sideroxylon obtusifolium in caatinga area. The study was conducted from October 2003 to September 2005, in natural populations of S. obtusifolium in Legal Reserve Area of the Project Salitre, municipality of Juazeiro, state of Bahia, Brazil. The phenological data showed that vegetative phenophases (sprouting and leaf senescence) occurred throughout the year, while flowering and fruiting were recorded in the dry and rainy seasons, respectively. The flowers are hermaphrodite, cream color, exhale odor, secrete small amount of nectar $(<1 \mu L)$, have diurnal anthesis and protogynous dichogamy. Among the floral visitors, bees, wasps, flies and butterflies were recorded. Apis mellifera and dipteral morphospecies 1 and 2 were considered as pollinators of this specie. The reproduction system of $\mathbf{S}$. obtusifolium is facultatively autogamous, producing fruit by self-pollination (6.6\%) and by cross-pollination (33\%). Differences in phenological registry, floral biology and the pollinators agents were found when compared with other environments, indicating that the climatic variables can be one of several factors that influence this relationship.
\end{abstract}

Keywords: Caatinga; Protogynous; Myophily.

\footnotetext{
${ }^{1}$ Recebido em 21.01.2014 aceito para publicação em 22.09.2014.

${ }^{2}$ Empresa Brasileira de Pesquisa Agropecuária, Centro de Pesquisa Agropecuária do Trópico Semi Árido, Embrapa Semi Árido, Petrolina, PE - Brasil. E-mail: <lucia.kiill@embrapa.br>

${ }^{3}$ Programa de Pos-Graduação em Recursos Genéticos Vegetais, Universidade Estadual de Feira de Santana - UEFS, Feira de Santana, BA - Brasil.E-mail: <carltaty@yahoo.com.br>.

${ }^{4}$ Instituto De Pós Graduação Extensão E Consultoria, IPEC, Brasil. E-mail: <paloma_pereira63@hotmail.com>.
} 


\section{INTRODUÇÃO}

O gênero Sideroxylon L. pertence à família Sapotaceae, sendo composto por cerca de 75 espécies de hábito arbóreo e arbustivo, distribuídas nas regiões tropicais e subtropicais (FRANCESCHINI, 2007), sendo os estudos ecológicos com esse grupo escassos e pouco recentes.

Popularmente conhecida como quixabeira, ou rombe-gibão, Sideroxylon obtusifolium (Roem. \& Schult.) T. D. Penn. é uma espécie que habita as margens de cursos de água ou as várzeas úmidas de solos aluviais pesados (LACERDA et al., 2005). A ocorrência dessa espécie é registrada desde o México até a Argentina, especialmente em áreas mais secas (PENNINGTON, 1990). No Brasil, S. obtusifolium ocorre na restinga da costa litorânea do Ceará e do Rio Grande do Sul (FERREIRA, 2000), no pantanal mato-grossense e na região da caatinga (LORENZI, 1998), sendo muito frequente no Vale do São Francisco. Neste último local, os ramos longos e resistentes a quebras são usados pelos barqueiros como varas para empurrar as barcas rio acima e nas manobras de atracação. Devido à pressão extrativista, a espécie é considerada ameaçada de extinção, sendo classificada como vulnerável (IBAMA, 1992).

Quanto aos estudos fenológicos, poucos são os relatos na literatura sobre o gênero. $\mathrm{Na}$ Costa Rica, a floração e frutificação de Sideroxylon capiri (A. DC.) Pittier foram registradas anualmente, com variação de magnitude dessas fenofases tanto entre estações do ano quanto entre os indivíduos (GARCIA; STEFANO, 2005). No Brasil, em Alagoinha, PE, a floração de Bumelia sartorum Mart. (= S. obtusifolium) foi relatada na estação chuvosa, com frutificação no período chuvoso e formação de folhas novas na transição do período chuvoso para o seco (BARBOSA et al., 1989, 2003). Na restinga de Maricá, RJ, Gomes et al. (2008), em estudos com a subespécie obtusifolium, registraram padrão anual das fenofases reprodutivas, com correlação significativa positiva entre floração e frutificação com os fatores abióticos.

No que se refere ao sistema sexual, existem registros de protoginia para Bumelia salicifolia (L.) Sw. (= Sideroxylon salificifolium (L.) Lam.) (TOMLINSON, 1974) e para S. obtusifolium em subsp. obtusifolium (GOMES et al., 2010). Abelhas e vespas foram consideradas como polinizadores efetivos dessa subespécie em área de Restinga (GOMES et al., 2010). Em estudos com $S$. cinereum e $S$. puberulum nas Ilhas Mauritius, pássaros e insetos (abelhas, moscas) foram observados entre os visitantes florais (HANSEN et al., 2002).

Neste trabalho são apresentadas informações sobre a fenologia, a biologia floral e os visitantes florais de Sideroxylom obtusifolium em área de caatinga, com o objetivo de responder às seguintes questões: Qual o comportamento fenológico dessa espécie em condições semiáridas? Quais visitantes florais são capazes de promover a polinização dessa sapotácea nessas condições? Há diferenças na biologia reprodutiva da espécie de acordo com ambiente (caatinga $\mathrm{x}$ restinga)?

\section{MATERIAL E MÉTODOS}

As observações foram feitas na Reserva Legal do Projeto Salitre (coordenadas em torno do ponto $09^{\circ} 30^{\prime} 21^{\prime \prime S}$ e 40 30'21"W), localizada no distrito de Juremal, Município de Juazeiro, no Noroeste do Estado da Bahia, que apresenta área total de 13.474 ha. De acordo com a classificação de Köppen, o clima da área se enquadra no tipo BSwh', com temperatura média anual de $26,4^{\circ} \mathrm{C}$. Na região, a precipitação média anual dos últimos 20 anos foi de $529 \mathrm{~mm}$, com a estação chuvosa registrada no período de novembro a abril (TEIXEIRA, 2010). Os dados meteorológicos do período das observações foram obtidos na Estação Meteorológica do Campo Experimental de Mandacaru da Embrapa Semiárido e utilizados para verificar a influência desses sobre o comportamento fenológico da espécie.

Para os estudos fenológicos, 20 indivíduos de S. obtusifolium foram selecionados e observados, quinzenalmente, de outubro de 2003 a setembro de 2005 para acompanhamento fenológico, quando foram coletadas informações sobre as fenofases vegetativas e reprodutivas. Considerou-se período de floração aquele em que a planta apresentava somente botões ou botões e flores abertas, enquanto na frutificação foi considerado o período em que a planta apresentava desde frutos em estádio inicial até frutos maduros. A fenofase de senescência foi considerada quando um indivíduo apresentava mais de $50 \%$ das folhas com coloração amarela ou seca.

Para avaliar os eventos fenológicos foi utilizado o método direto qualitativo (D'EÇA NEVES; MORELLATO, 2004), com observação visual dos 
indivíduos, em que as fenofases foram mensuradas e quantificadas por meio da média dos valores atribuídos aos indivíduos observados em campo. Os valores foram expressos em porcentagem, de acordo com as ocorrências das fenofases apresentadas por cada individuo da população quando manifestada no mês monitorado. O pico de determinado evento fenológico foi considerado quando mais de $50 \%$ dos indivíduos apresentaram a mesma fenofase (MORELLATO et al., 1989).

Para o estudo da morfologia, 20 flores foram observadas em diferentes estádios de desenvolvimento, desde botão até a senescência da flor. Dez flores foram coletadas e mensuradas, com auxílio de paquímetro digital, para verificar o comprimento e diâmetro dos componentes do cálice, da corola, bem como a posição e tamanho das estruturas reprodutivas.

Dados sobre a posição da inflorescência na planta, número de botões, sequencia e abertura das flores e número de flores abertas por dia também foram registrados. A receptividade do estigma foi testada segundo Dafni (1992). Para estimar a viabilidade dos grãos de pólen, lâminas com anteras foram preparadas e coradas com carmim acético 1,2\% (RADFORD et al., 1974). Para estimar a produção de néctar, 20 botões em pré-antese foram cobertos com sacos de papel impermeável, sendo as flores coletadas no final da tarde, quando foi medido o volume total de néctar por flor (KEARNS; INOUYE, 1993).

Para determinar a estratégia reprodutiva da espécie foram realizados experimentos de polinização, em que botões em pré-antese foram emasculados, quando necessário, e ensacados com sacos de papel impermeável. Logo após a antese, as flores foram submetidas aos tratamentos de autopolinização espontânea $(n=30)$, autopolinização manual $(\mathrm{n}=30)$, apomixia $(\mathrm{n}=30)$ e polinização cruzada $(n=30)$. Paralelamente, 30 flores mantidas em condições naturais foram marcadas para verificar a formação de frutos, servindo como controle. Após cada tratamento, as flores foram identificadas e novamente ensacadas e mantidas assim até a senescência floral. A porcentagem de frutos produzidos em cada experimento foi analisada por meio do teste de homogeneidade qui-quadrado $\left(\chi^{2}\right)$.

Os visitantes foram observados ao longo da floração, em dias não consecutivos, no período das $5 \mathrm{~h}$ às $18 \mathrm{~h}$, sendo anotados a frequência, o horário, o comportamento dos visitantes mais frequentes e o recurso floral forrageado. Para cada intervalo de observação foram feitas cinco repetições, no mínimo, totalizando $68 \mathrm{~h}$ de esforço amostral. As visitas observadas por intervalo foram somadas e, posteriormente, divididas pelo número de repetições, para calcular o número médio de visitas de cada intervalo.

De acordo com o comportamento apresentado, os visitantes florais foram considerados como polinizadores (DAFNI, 1992) ou pilhadores (INOUYE, 1980). Alguns visitantes foram capturados, fixados e mantidos a seco, para posterior identificação e exame dos locais de deposição do pólen. Os espécimes coletados foram depositados no Laboratório da Ecologia da Embrapa Semiárido.

\section{RESULTADOS}

Na área da Reserva Legal do Salitre, a população de Sideroxylon obtusifoliun estava distribuída às margens do riacho Baixão e apresentava porte arbóreo, com 6 a $10 \mathrm{~m}$ de altura, armada de fortes espinhos, tendo a ponta dos galhos pendentes. Os dados meteorológicos para essa região indicaram que, em 2004, foram registradas precipitações superiores a 500 $\mathrm{mm}$ em janeiro, enquanto em 2005 foram registrados valores em torno de $160 \mathrm{~mm}$ nos meses de fevereiro e março. Quanto às temperaturas médias, valores de 23,6 a $29,6^{\circ} \mathrm{C}$ foram registrados, indicando pequena variação desse fator ao longo do período (Figura 1a).

Os dados fenológicos mostraram que o brotamento foi registrado ao longo das observações (Figura 1b), exceto nos meses de novembro e dezembro de 2004 e fevereiro de 2005. Os valores variaram de 10 a $100 \%$, com pico observado na estação chuvosa. Taxas de 50 a $80 \%$ foram registradas ao longo da estação seca, indicando que para essa espécie a precipitação não é fator limitante para a produção de folhas.

A senescência foliar também foi registrada ao longo das observações com exceção de novembro de 2003, de janeiro a abril e em setembro de 2004. O pico dessa fenofase foi registrado de outubro de 2004 a setembro de 2005, com taxas de $100 \%$. Comparando a ocorrência dessa fenofase em 2004 e 2005, notou-se que no primeiro ano a perda das folhas se concentrou na estação seca, enquanto no ano seguinte esta foi registrada nas duas estações, com valores superiores aos registrados no ano anterior (Figura 1b).

Revista Árvore, Viçosa-MG, v.38, n.6, p.1015-1025, 2014 

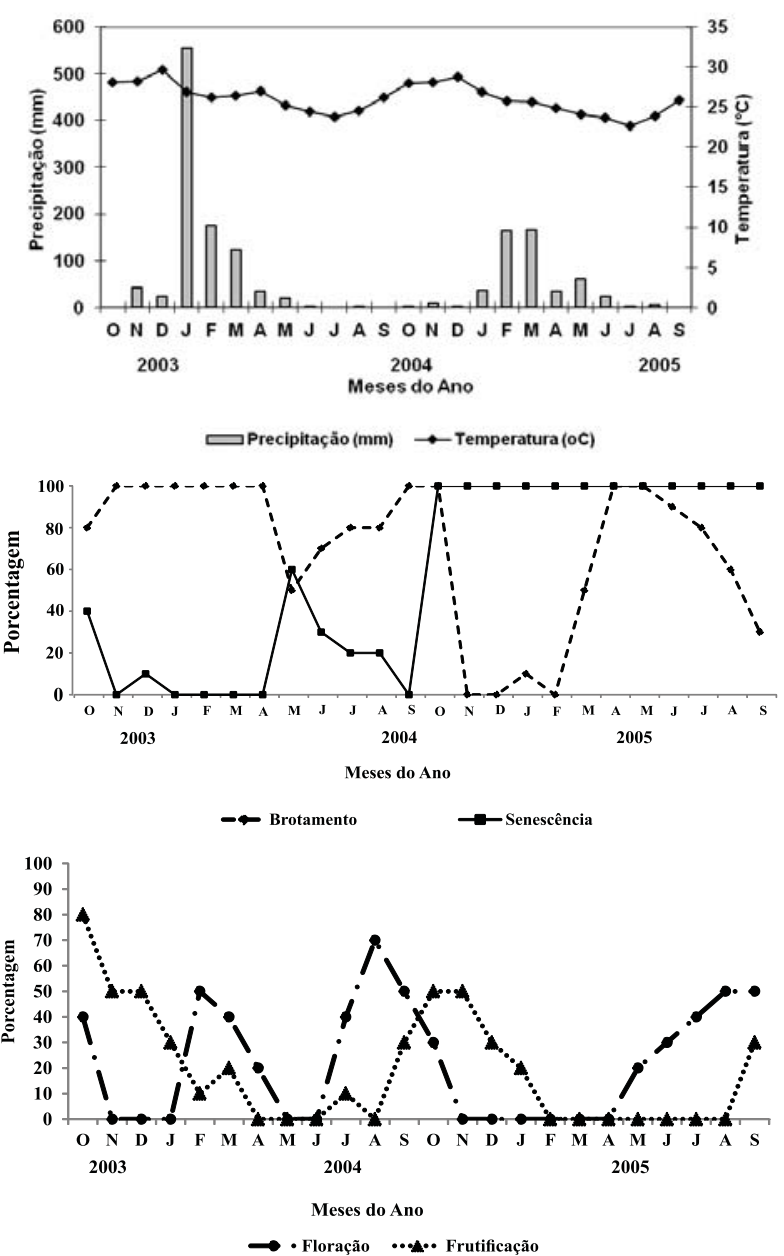

Figura 1 -a) Dados de temperatura $\left({ }^{\circ} \mathrm{C}\right)$ e precipitação $(\mathrm{mm})$ da Estação Meteorológica localizada no Campo Experimental de Mandacaru da Embrapa Semiárido, em Juazeiro, BA; Fenofases vegetativa (b) e reprodutiva (c) de Sideroxylon obtusifoliun na Reserva Legal do Projeto Salitre, em Juazeiro, BA, no período de 2003 a 2005.

Figure $1-$ a) Data of temperature $\left({ }^{\circ} \mathrm{C}\right)$ and rainfall $(\mathrm{mm})$ from the meteorological station located in the Experimental Area of Mandacaru of Embrapa Semiárido in Juazeiro, state of Bahia. Vegetative (b) and reproductive (c) phenophases of Sideroxylon obtusifolium in the Legal Reserve Area of the Project Salitre, in Juazeiro, BA, in the period 2003-2005.

A floração variou ao longo das observações, com registro em outubro de 2003, de fevereiro a abril (estação chuvosa) e de julho a outubro de 2004 (estação seca) e de maio a setembro de 2005 (final da estação chuvosa e início da seca). O pico de produção de flores (70\%) foi registrado em agosto de 2004, quando a precipitação foi praticamente nula e a temperatura média, de $24,5^{\circ}$ C (Figura 1c). A produção de frutos foi observada na transição da estação seca para a chuvosa, com taxas que variaram de 50 a $80 \%$, sendo o pico dessa fenofase registrado em outubro de 2003 (Figura 1c).

As flores de $S$. obtusifoliun encontravam-se agrupadas em fascículos axilares contendo de cinco a 25 botões (Figura 2a). Essas eram pentâmeras, hermafroditas, pequenas (5,0 $\mathrm{mm}$ de diâmetro) e apresentavam simetria radial. A corola apresentava coloração creme e formato raso campanulado, e cada pétala se apresentava dividida em três lacínios, sendo um mediano e dois laterais. No primeiro, encontrava-se alojado o estame e, juntamente com aqueles, constituía o mecanismo de liberação explosiva dos grãos de pólen.

$\mathrm{O}$ androceu era composto por cinco estames e cinco estaminódios, que ficavam posicionados no centro das pétalas. Os filetes apresentavam coloração creme, e anteras eram bitecas, com deiscência rimosa e, quando maduras, apresentavam coloração castanho-clara. O gineceu era formado por um ovário súpero com 1,0 mm de diâmetro, pentaovulado e estilete único. O nectário apresentava-se pouco desenvolvido, em forma de estrutura anelar, que circundava o ovário.

A antese floral de S. obtusfolium foi caracterizada por apresentar diferentes fases. Ainda no botão em pré-antese ocorreu a exposição do estilete e estigma a partir das $4 \mathrm{~h} 30$, porém o mesmo não se encontrava receptivo. Somente por volta das $7 \mathrm{~h}$, observou-se alteração na coloração do estigma, que se tornava mais brilhante e viscoso (receptivo), caracterizando o início da fase feminina da flor, embora a corola ainda estivesse fechada (Figura 2a, no. 1).

Após aproximadamente $24 \mathrm{~h}$, iniciava-se o afastamento das pétalas da corola, expondo os estames ainda abrigados nos lacínios centrais (Figura 2a, $\mathrm{n}^{\circ} .2$ ). Nessa ocasião, a flor se tornava funcionalmente hermafrodita, pois o estigma continuava receptivo, os grãos de pólen apresentavam alta viabilidade $(99,6 \%)$ e estavam disponíveis nas anteras, que já se encontravam aptas para se deslocarem quando acionadas pelos polinizadores. Nessa fase, néctar em pequena quantidade $(<1,0 \mathrm{~mL})$ era secretado, sendo também percebida a emissão de odor adocicado. 


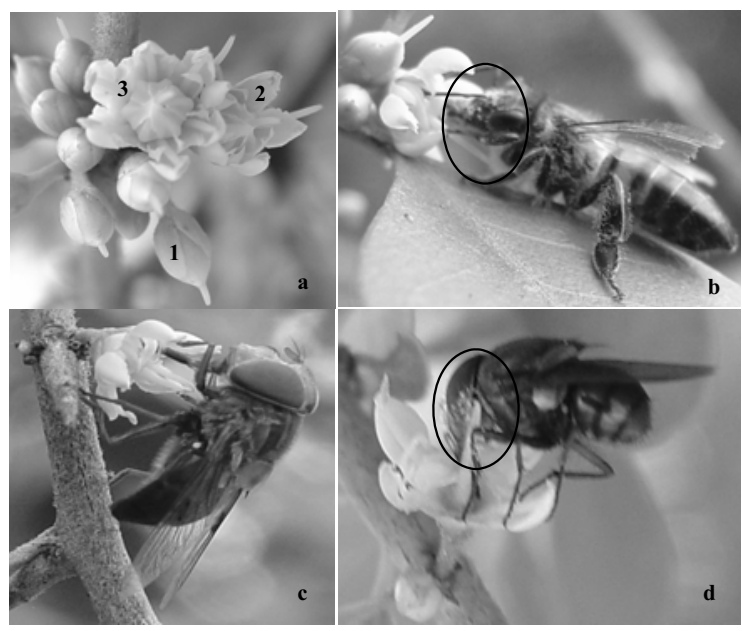

Figura 2 - Inflorescências de Sideroxylon obtusifolium (Sapotaceae). a) detalhe da inflorescência, mostrando flores em diferentes estádios. 1: flor na fase feminina; 2: flor em fase hermafrodita sem acionamento do mecanismo de exposição de pólen; 3: flor em fase hermafrodita com mecanismo acionado e anteras vazias. b) Belvosia bicincta c) díptero morfoespécie. 2.d) Belvosi abicincta. Notar deposição de pólen no corpo dos insetos (círculo).

Figure2 - Inflorescences of Sideroxylon obtusifolium (Sapotaceae). a) detail of inflorescence showing flowersat different stages. 1: flower in female phase, 2: flower in hermaphrodite phase without actuating the mechanism of pollen exposure; 3: flower in hermaphrodite phase with actuated mechanism and empty anthers. b) Apis mellifera; c) Diptera morphospecies 2, d) Belvosia bicincta. Note deposition of pollen on the insects body(circle).

A flor permanecia sem alterações por cerca de $48 \mathrm{~h}$ após a antese, quando se observavam todos os mecanismos de exposição acionados, e as anteras já não apresentavam grãos de pólen (Figura $2 \mathrm{a}, \mathrm{n}^{\circ} .3$ ). A partir dessa fase, observou-se a desidratação dos elementos florais, que podiam cair caso não houvesse fecundação. Do contrário, o gineceu permanecia envolto pelo cálice, o estilete e o estigma desidratavam e oxidavam, permanecendo até o desenvolvimento do fruto. Quanto à sequência de abertura das flores na inflorescência, verificou-se que os botões periféricos eram os primeiros a abrir, seguidos pelos botões centrais.

Os dados dos experimentos de polinização indicaram que não ocorreu formação de frutos nos experimentos de apomixia e autopolinização espontânea, sendo as maiores taxas registradas no experimento de polinização cruzada, com 33,0\% (Tabela 1). A análise estatística evidenciou que houve diferenças significativas entre os tratamentos.

As flores de $S$. obtusifolium foram visitadas por 17 espécies de insetos, entre himenópteros (8 espécies), dípteros ( 8 espécies) e lepidópteros (1 espécie), responsáveis por $60,9 \% ; 38,7 \%$; e $0,4 \%$ do total das visitas, respectivamente. Entre os himenópteros, as abelhas se destacaram, sendo responsáveis por $91,86 \%$ do total das visitas registrado para o grupo, com destaque para Apis mellifera, com 591 visitas registradas, corresponde a $55,4 \%$ do total das visitas e a $90,78 \%$ das visitas registradas para as abelhas. Entre os dípteros, as morfoespécies 1 e 2 se destacaram, totalizando 80,1\% das visitas registradas para o grupo (Tabela 2).

Com relação ao horário de visitas, verificou-se que A. mellifera esteve presente em todos os horários, com percentuais iguais ou superiores a $50 \%$, sendo o único visitante registrado das $5 \mathrm{~h}$ às $7 \mathrm{~h}$ e das $16 \mathrm{~h}$ às $17 \mathrm{~h}$. As visitas de Trigona spinipes foram registradas, principalmente, das $7 \mathrm{~h}$ às $8 \mathrm{~h}$, com percentuais pouco representativos na parte da tarde, e os dípteros foram registrados no final da manhã e início da tarde (Figura 3).

Durante as visitas, A. mellifera, T. spinipes, Belvosia bicincta e e os dípteros morfoespécie 1, 2 e 4 apresentaram comportamento semelhante na coleta de néctar (Figura 2b-d). Para isso, eles pousavam sobre a inflorescência, caminhavam sobre as flores à procura das que estavam abertas e, uma vez localizadas, introduziam o aparelho bucal entre os lacínios que recobriam o ovário, para ter acesso ao néctar. Durante essa movimentação, os

Tabela 1 - Resultados dos experimentos de polinização de Sideroxylon obtusifolium na Reserva Legal do Projeto Salitre, Juazeiro, BA. Fl:flor; Fr: fruto.

Table1 - Results of pollination experiments of Sideroxylon obtusifolium in the Legal Reserve Area of the Project Salitre, in the municipality of Juazeiro, state of Bahia. Fl: flower; Fr: fruit.

\begin{tabular}{lcc}
\hline Experimentos de polinização & Fl/Fr & $\%$ \\
\hline Condições Naturais & $30 / 03$ & $10,0 \mathrm{a}$ \\
Autopolinização espontânea & $30 / 00$ & 0,0 \\
Autopolinização manual & $30 / 02$ & $6,6 \mathrm{~b}$ \\
Apomixia & $30 / 00$ & 0,0 \\
Polinização cruzada & $30 / 10$ & $33,0 \mathrm{c}$ \\
\hline
\end{tabular}

Valores seguidos de mesma letra na coluna não diferem pelo teste qui-quadrado $\left(\chi^{2}\right)$, com 1 grau de liberdade e $\alpha=5 \%$.

Values followed by the same letter in the column do not differ by chi-square test $\left(\chi^{2}\right)$ with 1 degree of freedom and $\alpha=5 \%$. 
Tabela 2 - Visitantes florais de Sideroxylon obtusifolium observados na Reserva Legal do Projeto Salitre, Juazeiro, BA. $\mathrm{N}=$ néctar; $\mathrm{PI}=$ pilhador; e $\mathrm{PO}=$ polinizador.

Table 2 - Floral visitors of Sideroxylon obtusifolium observed in the Legal Reserve Area of the Project Salitre, in the municipality of Juazeiro, state of Bahia. $N=$ nectar, $P I=$ nectar thief, and $P O=$ pollinator.

\begin{tabular}{|c|c|c|c|c|}
\hline Visitantes Florais & $\mathrm{N}^{\circ}$. de visitas & $\%$ & Recurso floral & Classif. \\
\hline \multicolumn{5}{|l|}{ Himenóptera } \\
\hline Apis mellifera & 591 & 55,4 & $\mathrm{~N}$ & $\mathrm{PO}$ \\
\hline Trigona spinipes & 4 & 0,4 & $\mathrm{~N}$ & $\mathrm{PO}$ \\
\hline Frieseomelita doederleini & 3 & 0,3 & $\mathrm{~N}$ & P I \\
\hline Brachygastra $\mathrm{sp}$ & 1 & 0,1 & $\mathrm{~N}$ & PI \\
\hline Vespidae sp 1 & 33 & 3,0 & $\mathrm{~N}$ & P I \\
\hline Vespidae sp 2 & 11 & 1,0 & $\mathrm{~N}$ & P I \\
\hline Vespidae sp 3 & 6 & 0,5 & $\mathrm{~N}$ & PI \\
\hline Vespidae sp 5 & 2 & 0,2 & $\mathrm{~N}$ & PI \\
\hline Subtotal & 651 & 60,9 & & \\
\hline \multicolumn{5}{|l|}{ Díptera } \\
\hline Belvosia bicincta & 9 & 0,8 & $\mathrm{~N}$ & $\mathrm{PO}$ \\
\hline Morfoespécie. 1 & 128 & 12,0 & $\mathrm{~N}$ & $\mathrm{PO}$ \\
\hline Morfoespécie 2 & 202 & 19,0 & $\mathrm{~N}$ & $\mathrm{PO}$ \\
\hline Morfoespécie 4 & 18 & 1,7 & $\mathrm{~N}$ & $\mathrm{PO}$ \\
\hline Morfoespécie 5 & 43 & 4,0 & $\mathrm{~N}$ & P I \\
\hline Morfoespécie 6 & 6 & 0,6 & $\mathrm{~N}$ & PI \\
\hline Morfoespécie 7 & 5 & 0,5 & $\mathrm{~N}$ & PI \\
\hline Morfoespécie 8 & 1 & 0,1 & $\mathrm{~N}$ & PI \\
\hline Subtotal & 412 & 38,7 & & \\
\hline \multicolumn{5}{|l|}{ Lepidóptera } \\
\hline Morfoespécie 1 & 4 & 0,4 & $\mathrm{~N}$ & PI \\
\hline Total & 1067 & 100,0 & & \\
\hline
\end{tabular}

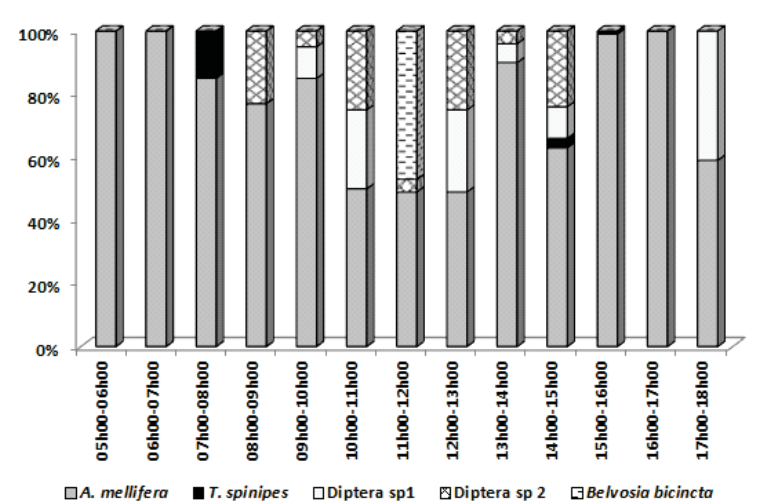

Figura 3-Principais visitantes florais de Sideroxylon obtusifolium, por horário, observados na Reserva Legal do Projeto Salitre, em Juazeiro, BA.

Figure 3 - Main floral visitors of Sideroxylon obtusifolium by time observed in the Legal Reserve Area of the Project Salitre, in the municipality of Juazeiro, state of Bahia.

insetos tocavam o estigma da flor com a parte ventral do corpo e, ou, região frontal e lateral da cabeça. Nessa ocasião, os insetos também acionavam o mecanismo de exposição de pólen, havendo a liberação dos grãos sob os seus corpos. Os demais visitantes florais ao realizarem suas visitas não tocavam o estigma, sendo, então, considerados como pilhadores de néctar.

\section{DISCUSSÃO}

Neste estudo, a população de S. obtusifolium apresentou produção e queda contínua de folhas e, por isso, foi considerada como decídua facultativa, concordando, assim, com os dados de literatura (OLIVEIRA et al., 1988; BARBOSA et al., 1989, 2003; MACHADO et al., 1990). Como a ocorrência dessa espécie está associada à vegetação ciliar, esta poderia estar proporcionando condições para que a produção de folhas ocorresse por um tempo mais longo, mesmo em ambientes mais secos como a caatinga.

Quanto à floração, esta ocorreu principalmente na estação seca, diferindo das observações feitas em Alagoinha, PE, por Barbosa et al. (1989, 2003), que registraram a presença dessa fenofase durante a estação chuvosa. Para as espécies da caatinga, a ocorrência dessa fenofase durante o período seco não é considerada

Revista Árvore, Viçosa-MG, v.38, n.6, p.1015-1025, 2014 
como regra e, segundo Machado (1990), entre as espécies estudadas, somente $30 \%$ apresentou floração nessa época do ano.

Na restinga de Maricá, RJ, a floração de $S$. obtusifolium subsp. obtusifolium foi observada nos meses de agosto a novembro, considerado como transição do período menos úmido para o chuvoso (GOMES et al., 2008), inverso ao observado neste estudo e similar ao observado por Barbosa et al. (1989).

No que se refere à produção de frutos, esta foi registrada na transição da estação seca para a chuvosa, diferindo do padrão observado por Barbosa et al. (1989), que registraram a frutificação dessa sapotácea no período de maio a julho, considerado como estação chuvosa. Gomes et al. (2008) verificaram que a produção de frutos de $S$. obtusifolium subsp. obtusifolium variou ao longo das observações, sendo registrado de outubro a março nos estudos feitos na restinga de Maricá, RJ.

Diante do exposto, verificou-se que há variações no padrão de floração e de frutificação de S. obtusifolium nos diferentes ambientes, podendo este estar relacionado com as condições climáticas de cada região.

Os estudos fenológicos realizados para a família Sapotaceae indicam que há diferentes padrões de frutificação (FALCÃO; CLEMENT, 1999; GARCIA; DI STEFANO, 2005), com maior ocorrência na estação chuvosa (ALENCAR, 1990, 1994; BIANCHI et al., 2006). De acordo com Alencar (1994), a disponibilidade de água parece ser uma necessidade importante para a frutificação das espécies dessa família que apresentam frutos carnosos e podem ser consideradas como importante fonte alimentar para a avifauna da caatinga (KIILL et al., 2012).

Morfologicamente, as flores de S. obtusifolium apresentam características similares a $S$. obtusifolium subsp. obtusifolium (GOMES et al., 2010), enquadrandose no tipo Sideroxylon (PENNINGTON, 1991). Com relação à biologia floral e aos mecanismos de polinização, S. obtusifolium apresentou dicogamia protogínica incompleta, caracterizada por um período em que somente o estigma está receptivo (fase feminina), seguida por uma fase em que estigma e grãos de pólen são apresentados (fase hermafrodita), semelhante ao descrito por Gomes et al. (2010) para S. obtusifolium subsp. obtusifolium.
Quanto à antese floral, esta foi registrada nas primeiras horas da manhã, diferindo de Gomes et al. (2010), que observaram o processo de abertura dos botões em diferentes horas do dia. Esse fato pode estar relacionado às condições climáticas da região que, neste estudo, por serem mais áridas, poderia ter acelerado esse processo para esse horário, quando geralmente é registrada maior atividade dos visitantes florais na caatinga (MACHADO, 1990). No que se refere à produção de néctar, esta foi observada em pequenas quantidades, característica também registrada para outras Sapotaceae, indicando que o pequeno volume desse recurso pode ser importante para que os polinizadores dessas espécies visitem várias flores e se movimentem mais entre as plantas, favorecendo a geitonogamia e xenogamia (GAMA et al., 2011).

Os dados obtidos nos experimentos de polinização mostraram que não ocorreu agamospermia nessa espécie, sendo necessário um vetor de pólen para que ocorra a formação de frutos. As maiores taxas foram registradas no experimento de polinização cruzada e a formação de frutos somente nos experimentos de autopolinização manual indica que, embora a espécie seja autocompatível, é necessário um vetor para que haja deposição de pólen sobre o estigma. A taxa de frutificação em condições naturais (controle) foi relativamente baixa, indicando que há baixa produção de frutos em relação ao grande número de flores produzidas.

$\mathrm{Na}$ literatura, estudos com sistema de reprodução de Sapotaceae são poucos e relatam a ausência de agamospermia e predominância de xenogamia, concordando com os dados aqui obtidos. Em estudos realizados no Cerrado, Gama et al. (2011) relataram que as duas espécies de Pouteria estudadas são autoestéreis e não agamospérmicas e apresentaram baixo sucesso de frutificação na polinização aberta. Araújo (2008), em estudos com subespécie de Micropholis guayanesis (Sapotaceae), na Reserva Florestal de Duke em Manaus, AM, observou maior formação de frutos nos experimentos de polinização cruzada do que no controle, indicando que poderia haver déficit de polinização, fato que também poderia estar ocorrendo na situação deste estudo.

No que se refere aos visitantes, a diversidade de insetos aqui registrada (17 espécies) foi maior quando comparada com as observações feitas na restinga de Maricá, RJ (GOMES et al., 2010) e Perichón-Argentina (FRANCESCHINI, 2007). Entre os himenópteros, o maior

Revista Árvore, Viçosa-MG, v.38, n.6, p.1015-1025, 2014 
número de espécies foi registrado na caatinga, com cinco espécies de vespas e três abelhas. Já na restinga foram registradas seis espécies, sendo três abelhas, uma vespa e duas formigas. Estes últimos insetos também foram observados em visitas ocasionais na Argentina, porém não visitando as flores de S. obtusifolium na caatinga.

Quanto aos dípteros, a maior diversidade também foi registrada na caatinga, com oito espécies. Na restinga, esse grupo não foi observado, e, na Argentina, somente duas morfoespécies foram registradas. Entretanto, o registro de besouros e tripes foi constatado somente na restinga, não havendo registro deles neste estudo. No primeiro caso, a ausência de visitas pode estar relacionada com a metodologia adotada, uma vez que esses besouros visitam as flores somente à noite, horário em que não foram feitas observações na caatinga.

De modo geral, para himenópteros e dípteros, a maior diversidade de visitantes florais de $S$. obtusifolium foi encontrada na caatinga e pode estar relacionada ao fato de a floração ter ocorrido, principalmente, na estação seca, época em que há menor oferta de recursos florais, o que levaria a entomofauna a concentrar suas visitas nas espécies que apresentam essa fenofase nesse período (KIILL et al., 2010).

Quanto ao horário das visitas, os dípteros foram registrados no final da manhã e início da tarde neste estudo, concordando com as observações feitas por Franceschini (2007). Outros estudos feitos com esses insetos relataram que os picos de sua atividade podem ocorrer durante a manhã, próximos ao meio-dia (MORSE, 1981; GILBERT, 1985), antes e depois do meio dia (ARRUDA et al., 1998), à tarde e ao crepúsculo (WILLMER, 1983). Segundo Gilbert (1985), essas diferenças na periodicidade estão certamente relacionadas aos tipos de atividade dos espécimes estudados e a fatores climáticos.

Nas observações feitas na caatinga, a frequência de visita dos dípteros foi inversamente proporcional à de $A$. mellifera, indicando que a presença dessa abelha poderia estar influenciando negativamente a visitação das moscas. Em observações feitas para S. cinereum Lam. e $S$. puberulum DC., espécies dioicas e ornitófilas das Ilhas Maurício, Hansen et al. (2002) também verificaram que $A$. mellifera interferiu nas interações endêmicas entre as duas espécies e os dois pássaros considerados agentes polinizadores.
Assim, a presença dessa abelha exótica poderia estar deslocando os polinizadores efetivos de Sideroxylon obtusifolium.

De modo geral, os visitantes mais frequentes foram A. mellifera e os dípteros morfoespécies 1 e 2, concordando com as observações feitas por Franceschini (2007), na Argentina. Já Gomes et al. (2010), no estudo feito na restinga de Maricá, RJ, observaram que, além da abelha melífera, a borboleta Isanthrene incendiaria e os coleópteros Astylus lineatus e Oedemeridae foram os visitantes mais frequentes, embora esses últimos tenham sido considerados como pilhadores de néctar.

De acordo com o comportamento e frequência de visita apresentado, A. mellifera e os dípteros morfoespécies 1 e 2 foram considerados com polinizadores de Sideroxylon obtusifolium na Reserva Legal do Projeto Salitre. Trigona spinipes, Belvosia bicincta e o díptero morfoespécie 4, apesar de apresentarem comportamento adequado, foram considerados como polinizadores ocasionais, em virtude de baixa frequência apresentada.

Em estudos realizados na Argentina, as abelhas melíferas e duas espécies de dípteros foram também consideradas como principais polinizadores de $S$. obtusifolium subsp. obtusifolium (FRANCESCHINI, 2007), concordando com os registros feitos em área de caatinga. Na restinga, Gomes et al. (2010) consideraram as abelhas Xylocopa ordinaria e Apis mellifera, a vespa Brachygastra lecheguana e a borboleta Isanthrene incendiaria como os polinizadores efetivos dessa mesma subespécie, mostrando que pode haver diferenças no grupo de polinizadores, dependendo da região em que a planta se encontra.

Neste estudo, $A$. mellifera foi o polinizador mais frequente e abundante, similar ao registrado em outros estudos feitos na caatinga (MACHADO, 1990; KIILL et al., 2010; KIILL; BIANCHINI, 2011), reforçando a indicação de abelha altamente generalista, cuja dieta inclui plantas dos mais diversos grupos.

Com relação aos dípteros, poucos relatos são encontrados em literatura para a caatinga. De acordo com Machado e Lopes (2003), em levantamento feito para esse ecossistema, somente $12,4 \%$ das plantas foram consideradas como polinizadas por diversos pequenos insetos, e as autoras não citaram a ocorrência de sistemas

Revista Árvore, Viçosa-MG, v.38, n.6, p.1015-1025, 2014 
de polinização por moscas. Dessa forma, o registro da polinização de Sideroxylon obtusifolium por dípteros pode ser considerado como um dos primeiros relatos para a caatinga.

\section{CONCLUSÃO}

Sideroxylon obtusifolium apresentou comportamento fenológico reprodutivo diferente do registrado em outras regiões, com floração na estação seca e frutificação na estação chuvosa, sendo considerada importante fonte alimentar para polinizadores e dispersores da caatinga. Apis mellifera e os dípteros foram considerados como polinizadores dessa sapotácea que, embora seja autocompatível, apresenta maior formação de frutos por polinização cruzada. Diferenças no comportamento fenológico, na biologia floral e nos agentes polinizadores indicam as variáveis climáticas como um dos diversos fatores capazes de influenciar essa relação.

\section{REFERÊNCIAS}

ALENCAR, J. C. Interpretação fenológica de espécies lenhosas de Campina na Reserva Biológica de Campina do INPA ao Norte de Manaus. Acta Amazonica, v.20, p.145-183, 1990

ALENCAR, J. C. Fenologia de cinco espécies arbóreas tropicais de Sapotaceae correlacionadas a variáveis climáticas na Reserva Ducke, Manaus, AM. Acta Amazonica, v.24, n. 3/4, p.161-182, 1994.

ARAÚJO, M. H. T. Estudos taxonômicos das subespécies Micropholis guayanensis e (A.D.C.) Pierre subsp. guayanensis, Micropholis guayanensis e (A.D.C.) Pierre subsp. duckeana (Baehni) Penn. e Micropholis guayanensis e (A.D.C.) Pierre subsp. 3 (Sapotaceae Juss.): uma abordagem biossistemática. 2008. 98f. Dissertação (Mestrado em Biologia Vegetal) Instituto Nacional de Pesquisa da Amazônia/Universidade Federal do Amazonas, 2008.

ARRUDA, V. L. V.; SAZIMA, M.;

PIEDRABUENA, A. E. Padrões diários de atividade de sirfídeos (Diptera, Syrphidae) em flores. Revista Brasileira de

Entomologia, v.41, n.2-4, p.141-150, 1998.
BARBOSA, D.C.A.; ALVES, J.L.H.; PRAZERES, S.M.; PAIVA, A.M.A. Dados fenológicos de 10 espécies arbóreas de uma área de caatinga (Alagoinha-PE). Acta Botânica Brasílica, v.3, n.2, p.109-118, 1989.

BARBOSA, D. C. A.; BARBOSA, M. C. A.; LIMA, L. C. M. Fenologia de espécies lenhosas da Caatinga. In: LEAL, I. R.; TABARELLI, M.; SILVA, J. M. C. (Ed.). Ecologia e conservação da Caatinga. Recife : Ed. Universitária da UFPE, 2003. p.657-694.

BIANCHI, E.; PIMENTA, J. A.; SANTOS, F. A. M. Fenologia de Chrysophyllum gonocarpum (Mart. \& Eichler) Engl. (Sapotaceae) em floresta semidecídua do Sul do Brasil. Revista Brasileira de Botânica, v.29, n. 4, p.595-602, 2006.

DAFNI, A. Pollination ecology: a practical approach (the practical approach series). New York: University Press, 1992. 250p.

D'EÇA-NEVES, F. F.; MORELLATO, L. P. C. Métodos de amostragem e avaliação utilizados em estudos fenológicos de florestas tropicais. Acta Botânica Brasílica, v.18, n.1, p.99-108, 2004.

FALCÃO, M. A.; CLEMENT, C. R. Fenologia e produtividade do abiu (Pouteria caimito) na Amazônia Central. Acta Amazonica, v.29, n.1, p.3-11, 1999.

FERREIRA, R. C. N. Espécies arbóreas ameaçadas de extinção das restingas do norte fluminense. Considerações sobre sua conservação mediante ao emprego paisagístico. 2000. 124 f. Dissertação (Mestrado em Botânica) Universidade Federal do Rio de Janeiro/Museu Nacional, Rio de Janeiro, 2000.

FRANCESCHINI, M. C. Fases florales, nectario y visitantes en Sideroxylon obtusifolium (Roem. \& Schult.) T.D. Penn. (Sapotaceae). Instituto de Botánica del Nordeste (IBONE) - Facultad de Ciencias Agrarias - UNNE, 2007. Disponível em: $<$ http:// www1.unne.edu.ar/cyt/2002/06-Biologicas/B014.pdf $>$ Acesso em: 12 abr. 2007.

GAMA, L. U.; BARBOSA, A. A. A.; OLIVEIRA, P. E. A. M. Sistema sexual e biologia floral de Pouteria ramiflora e P. torta (Sapotaceae).

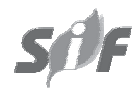

Revista Árvore, Viçosa-MG, v.38, n.6, p.1015-1025, 2014 
Revista Brasileira de Botânica, v.34, n.3, p.375-387, 2011.

GARCIA, E. G.; DI STEFANO, J. F. Fenologia del árbol Sideroxylon capiri (Sapotaceae) en el Bosque Seco Tropical de Costa Rica. Revista de Biologia Tropical, v.53, n.1-2, p.5-14, 2005.

GILBERT, F. S. Diurnal activity patterns in hoverflies (Diptera: Syrphidae). Ecological Entomology, v.10, n. 4, p.385-392, 1985.

GOMES, R.; PINHEIRO, M. C. B.; LIMA, H. A. Fenologia reprodutiva de quatro espécies de Sapotaceae na restinga de Maricá, RJ. Revista Brasileira de Botânica, v.31, n.4, p.679-687, 2008.

GOMES, R.; PINHEIRO, M.C.B.; LIMA, H.A.; SANTIAGO-FERNANDES, L.D.R. Biologia floral de Manilkara subsericea e de Sideroxylon obtusifolium (Sapotaceae) em restinga. Revista Brasileira de Botânica, v.33, n.2, p.271-283, 2010.

HANSEN, D. M.; OLESEN, J. M.; JONES, C. G. Trees, birds and bees in Mauritius: exploitative competition between introduced honey bees and endemic nectarivorous birds? Journal of Biogeography, v.29, n. 5/6, p.721-734, 2002.

IBAMA. Plano de manejo florestal para a região do Seridó do Rio Grande do Norte. Natal: IBAMA, 1992. v.1. (Projeto PNUD/ FAO/IBAMA).

INOUYE, D. W. The terminology of floral larceny. Ecology, v.61, n. 5, p.1251-1253, 1980.

KEARNS, C. A.; INOUYE, D. W. Techniques for pollination biologists. Niwot, CO: The University Press of Colorado, 1993. 559p.

KIILL, L. H. P.; BIANCHINI, R. S. Biologia reprodutiva e polinização de Jacquemontia nodiflora (Desr.) G. Don (Convolvulaceae) em Caatinga na região de Petrolina, PE, Brasil. Hoehnea, v.38, n.4, p.511-520, 2011.

KIILL, L. H. P.; MARTINS, C. T. V. D.; SILVA, P. P. Biologia reprodutiva de duas espécies de
Anacardiaceae da caatinga ameaçadas de extinção. In: ALBUQUERQUE, U. P.; MOURA, A. N.; ARAÚJO, E. L. (Ed.). Biodiversidade, potencial econômico e processos ecofisiológicos em ecossistemas nordestinos. Bauru: Canal 6, 2010 . v.2. p.337-364.

KIILL, L. H. P.; MARTINS, C. T. V. D.; SILVA, P. P. Morfologia e dispersão dos frutos de espécies da Caatinga ameaçadas de extinção. Petrolina: Embrapa Semiárido, 2012. 23p. (Embrapa Semiárido. Boletim de Pesquisa e Desenvolvimento, 97).

LACERDA, A. V.; NORDI, N.; BARBOSA, F.M.; WATANABE, T. Levantamento florístico do componente arbustivo-arbóreo da vegetação ciliar na bacia do rio Taperoá, PB, Brasil. Acta

Botânica Brasílica, v.19, n.3, p.647-656, 2005.

LORENZI, H. Árvores brasileiras: manual de identificação e cultivo de plantas arbóreas nativos do Brasil. 2.ed. Nova Odessa: Plantarum, 1998. 352p.

MACHADO, I. C. S. Biologia floral de espécies de Caatinga no município de Alagoinha (PE). 1990. 245f. Tese (Doutorado em Biologia Vegetal) - Universidade Estadual de Campinas, Campinas, 1990.

MACHADO, I. C. S.; LOPES, A. V. Recursos florais e sistemas de polinização e sexuais em Caatinga. In: LEAL, I. R.; TABARELLI, M.; SILVA, J. M. C. Ecologia e conservação da Caatinga. Recife: UFPE, 2003. p.515-563.

MORELLATO, L. P. C.; RODRIGUEZ, R.R.; LEITÃOFILHO, H.F.; JOLY, C.A. Estudo comparativo da fenologia de espécies arbóreas de floresta de altitude e floresta mesófila semidecídua na Serra do Japi, Jundiaí, São Paulo. Revista Brasileira de Botânica, v.12, n.1, p.85-98, 1989.

MORSE, D. H. Interactions among syrphid flies and bumblebees on flowers. Ecology, v.62, n.1, p.81-88, 1981.

PENNINGTON, T. D. Flora neotropica: Sapotaceae. New York: Organization for Flora Neotropica by Hafner Publishing Company, 1990. (Monograph, 52) 
PENNINGTON, T. D. The genere of

Sapotaceae. New York: Botanical Garden, 1991.

OLIVEIRA, J. G. B.; QUESADO, H.L.C; NUNES, E.P.; VIANA, F.A. Observações preliminares da fenologia de plantas da caatinga na estação ecológica de Aiuba. Mossoró: ESAM, 1988. (Coleção Mossoroenses, 538)

RADFORD, A. E.; DICKINSON, W.C.; MASSEY, J.R.; BELL, C.R. Vascular plant systematics. New York: Harper \& Row Publishers, 1974. 891p.
TEIXEIRA, A. H. C. Informações agrometeorológicas do polo Petrolina, PE/Juazeiro - 1963 a 2009. Petrolina:

Embrapa Semiárido, 2010.21p. (Embrapa Semiárido. Documentos, 233).

TOMLINSON, P. B. Breeding mechanisms in trees. Journal of the Arnold Arboretum, v.55, p.269-290, 1974.

WILLMER, P. G. Thermal constraints on activity patterns in nectar-feeding insects. Ecological Entomology, v.8, n. 4, p.455469, 1983. 
